\title{
The effect of plyometric training on performance levels of the shot put technique and its related motor abilities
}

\author{
Agron Thaqi $^{1 \mathrm{BD}}$, Milaim Berisha ${ }^{2 \mathrm{ACDE}}$, Isa Asllani ${ }^{\mathrm{AE}}$ \\ ${ }^{1}$ Tetovo State University, North Macedonia \\ ${ }^{2}$ Istanbul Gelisim University, Turkey \\ ${ }^{3}$ Tetovo State University, North Macedonia
}

Authors' Contribution: A - Study design; B - Data collection; C - Statistical analysis; D - Manuscript Preparation; E - Funds Collection

\begin{abstract}
Purpose:

The aim of this research is to evaluate the effects of plyometric training on the shot put technique. It was oriented to improve the basics for the development of power related-indicators such as power (explosive force), acceleration speed, and strength endurance.

Material: $\quad$ The study sample included 220 male students, aged 16 years \pm 6 months from Fehmi Lladrovci High School, Glogoc municipality, Republic of Kosovo from the 2019/2020 academic year. The experimental group (110 male students) applied a 12-week program (see the training program paragraph). The control group (110 male students) continued only with their regular physical education lessons (2 times a week). To determine the differences between pre- and post-test values of the control and experimental groups ANOVA calculations were made. The development percentage in time (between pre-test and post-test) were calculated using the formula: $\Delta \%=(\mathrm{x}$ post-test $-\mathrm{x}$ pre-test $) /$ pre-test ${ }^{*} 100$.

Results: $\quad$ Results of the study show that pre- and post-test average values (tests within subjects) of the shot put technique $(p<0.05)$ were statistically different according to measurement over time (interaction; $p<0.05)$, and in tests between the subjects $(p<0.05)$. The shot put technique $(\Delta \%: 50.88)$ test of the experimental group (plyo-training) had higher developmental percentages compared to ( $\Delta \%: 1.69)$ the control group $(p<0.05)$. When analyzing the developmental percentage, it was observed that the performance of the shot put technique of the experimental group compared the control group $49.2 \%$ more developed. Furthermore, the impact of the plyometric training program in motor abilities related to the shot put technique also observed similar improvements in the impact of the shot put technique.

Conclusions: $\quad$ In conclusion, the impact of the plyometric training program on motor abilities related to the shot put technique also observed similar results as the training program's impact on the shot put technique. The applied plyometric training program benefits were not just in the shot put technique but also improved all motor abilities related to the shot put technique such as power, strength endurance, speed and acceleration. Therefore, the development of the shot put technique occurred by an increase in motor abilities related to the shot put technique as a result of the plyometric training program.

Keywords: $\quad$ shot-put technique, plyometric training, power (explosive force), acceleration speed, strength endurance
\end{abstract}

\section{Introduction}

Athletics is an exclusive collection of sporting events that include races in running, jumping, throwing and walking. The most common types of athletics competitions take place on sports fields and also include street jogging, sports walking races, etc. Athletics is primarily an individual sport, with the exception of relay races and competitions, which combine team performance of athletes, or athlete scores, such as in cross-country [1].

Shot put is one of the four disciplines that are part of athletics throwing along with the discus throw, hammer throw and javelin. The shot put is an athletic throwing event that involves putting, or pushing, a heavy metal ball with one hand as far as possible. Shot putters use their strong quadriceps, hamstrings and gluteus maximus muscles to push off from the back of the circle and generate the initial thrust necessary to get the heavy metal shot moving across the circle.

Throwing involves an exact shot put technique based

(c) Agron Thaqi, Milaim Berisha, Isa Asllani, 2021

doi:10.15561/26649837.2021.0301 on explosive actions such as short sprinting, jumping, weightlifting, etc. Plyometric exercises are mainly used to increase maximum energy production and the ability to jump. Plyometric training programs include training loads with a number of jumps and intervals between sets of exercises and drills. In plyometric exercises, athletes perform various explosive actions, which help to improve their skills $[2,3]$.

Depending on the effect on the neuromuscular system and their biomechanical structure, trainers have categorized strength-training exercises for throwers as general or specific $[4,5]$. General exercises are those that aim to build a foundation by increasing maximum strength in specific muscles, especially the main movers, regardless of the range of motion, joint angle, or speed that may occur in the current event [6].

Performance on track and field throwing competitions depends to a large extent on the production of muscle power. Muscle power is a product of strength and speed, so each or both of these ingredients, should be addressed in a training program to develop muscle power. Both 
groups of athletes, beginners and elite throwers, spend a great deal of their preparation using conventional power training or various forms of energy training to increase muscular power and throwing performance. For beginner and intermediate-trained throwers, resistance training causes a significant increase in shot put performance [7].

Although, shot put is a dynamic event demanding high power production, one of the parameters that determines the power production of a muscle group (whole-body), is muscular strength. However, the relationship between strength and shot put performance has not been thoroughly examined [8]. In light of this information, we think that the shot put technique and its related factors should be examined in more detail. The aim of this research is to evaluate the effects of plyometric training on the shot put technique. It was oriented to improve the basics for the development of power related-indicators such as power (explosive force), acceleration speed, and strength endurance.

\section{Material and Methods}

\section{Participants}

The study sample included 220 male students, aged 16 years \pm 6 months from Fehmi Lladrovci High School, Glogoc municipality, Republic of Kosovo from the 2019/2020 academic year. The experimental group (110 male students) applied a 12-week program (see the training program paragraph). The control group (110 male students) continued only with their regular physical education lessons (2 times a week).

The study was conducted in a manner that respected the principles established by the Declaration of Helsinki and it was approved by the Ethics Committee of the University.

In the study, data collection tools were as folows. Countermovement jump (CMJ), Standing broad jump (SBJ), Tipple standing jump (TSJ), Standing medicine ball throw (SMBTH), 10 Meters run (10mRUN), 20 Meters run (20mRUN), Plate tapping (PLT), Foot-tapping against the wall (FTAW), Sit-ups in $30 \mathrm{sec}$ (SUP30s), Push-ups in $30 \mathrm{sec}$ (PU30s), Dips (D), Flamingo balance test (FB), and Performance levels of the shot-put technique.

\section{Testing Procedures}

Subjects were assessed before and after 12 weeks of the plyometric training program, all measurements were taken before the start of the training and after the end of the training. The tests were preceded by a general warm-up. Countermovement Jump (CMJ) was performed on a contact mat platform [9]. Standing Broad Jump (SBJ) and Standing Triple Jump (STJ) measurements were conducted according to the Nešić Protocol [10]. Standing medicine ball throw (SMBTH) is a test for assessment of explosiveness of the shoulder area (the results were obtained with an accuracy of $1 \mathrm{~cm}$ ) [10]. 10-meter and 20-meter sprint test measurements were performed according to the Bjelica and Fratric protocols (the result is given with an accuracy of $0.1 \mathrm{sec}$ ) [11]. Plate tapping (PLT) and foot-tapping against the wall (FTW) were used to measure movement speed individually and measured according to the standard procedure used in the euro-fit test battery [12]. The sit-ups in $30 \mathrm{sec}$ (SUP30s) test measured by bending the elbows from the straight position, then approaching the ground and straightening the elbows again; correctly done and completed sit-ups were counted and recorded [13]. Push-ups in $30 \mathrm{sec}$ (PU30s) have validity and reliability [14] to measure the muscular strength endurance of the chest and back arm muscles [14, 15]. General body balance was used by the Flamingo Balance (FLB). A metal beam $50 \mathrm{~cm}$ long, $4 \mathrm{~cm}$ high, and $3 \mathrm{~cm}$ wide were used in this test. During this test, the subject tries to maintain his posture like a flamingo for a long time by standing on the metal beam. For 1 minute, any intervention (that does not fall) made to maintain balance in the beam is considered as a point. The dips (D) test was performed in parallel for men placed in the gym. The subject is placed with support in the hands at the beginning of the parallel bars, with straight legs hanging down. The task of the test holder is from the position described above, as much as possible to perform parallel lifts. The maximum number of parallel rises is estimated. At the moment of ascent, the arms must be completely straight, respectively gathered during the phase of falling on the support. At the same time, the legs are straight. [16].

\section{Training Program}

The plyometric training program was prepared according to the National Strength and Conditioning Association (NSCA). The volume of the training varied between 85-120 contacts per session, intensity varied between low to high load and was applied 3-4 times per week (fig. 1). Bounding drills normally covered distances greater than 98 feet $(30 \mathrm{~m})$ or work time approximately
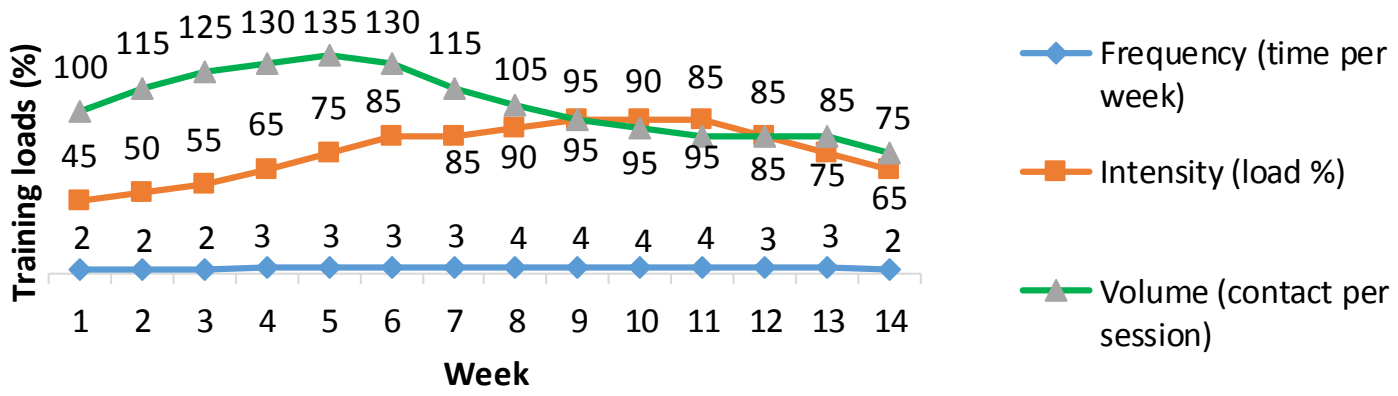

Figure 1. Plyometric training program loads 
20-25 sec, and box jumps were repeated 10-15 times. Recovery for depth jumps consisted of 5 to 10 seconds of rest between repetitions and 2 to 3 minutes between sets. The time between sets was determined by a proper work-to-rest ratio (i.e., 1:5 to 1:10) and was specific to the volume and type of drill being performed (tabl. 1).

For safety considerations, athletes who were more than $100 \mathrm{~kg}$ were not requested to lift $1 \mathrm{RM}$ squat minimum of 1.5 times his or her body weight, and to stand on one leg for 30 seconds without falling, and were not included in the plyometric training (tabl. 1).

When the training intensity in the lower extremities was low, moderate and low-severity exercises were applied in the trunk and upper body (fig. 2). The same rule applied when working with other parts of the body.

Statistical Analysis.

IBM SPSS Statistics 24 software was used for data analysis. To determine the differences between pre and post-test values of the control and experimental groups, ANOVA calculations were made. The development percentage in time (between pre-test and post-test) were calculated by using the formula " $\% \Delta=$ (x post-test $-\mathrm{x}$ pre- test) / pre-test $* 100 "$ where the confidence interval was chosen as $95 \%$ and values below $\mathrm{p}<0.05$ were considered statistically significant.

\section{Results}

According to the results of Table 2, it was observed that pre- and post-test averages (tests within subjects) of the shot put technique $(\mathrm{p}<0.05)$ tests values were statistically different according to measurement in time (interaction; $\mathrm{p}<0.05$ ). Similar results were observed in the tests between subjects $(\mathrm{p}<0.05)$. When analyzing the differences between the groups, it was observed that the shot put technique $(\Delta \%: 50.88)$ test of the experimental group (plyo-training) had higher development percentages compared to the shot put technique $(\% \Delta: 1.69)$ tests of the control group $(\mathrm{p}=.00)$.

According to the results of Table 3, it was observed that pre- and post-test averages (tests within subjects) of the countermovement jump $(\mathrm{p}<0.05)$, standing broad jump $(\mathrm{p}<0.05)$, triple standing jump $(\mathrm{p}<0.05)$ and standing medicine ball throw $(\mathrm{p}<0.05)$ test values were statistically different according to measurement over time

Table 1. Exercises included on the plyometric training program

\begin{tabular}{lll}
\hline Exercises & & \\
\hline Lower body exercises & Upper body exercises & Trunk exercises \\
Jump in place & Throws (power drop) & Medicine ball throw \\
Standing jumps & Plyometric push-ups & $45^{\circ}$ sit-up \\
$\begin{array}{l}\text { Multi hops and jumps (lateral } \\
\text { barrier hop) }\end{array}$ & Plyometric push-ups & V - sit ups (one rapid repetition) \\
$\begin{array}{l}\text { Bounds (leaping movement } \\
\text { upward) }\end{array}$ & Bench Press with Medicine Ball & \\
$\begin{array}{l}\text { Bounds (power skip) } \\
\text { Box drills }\end{array}$ & Depth Push-Ups (from Box) & Frog sit ups (one rapid repetition) \\
Depth jumps & Push-ups (gymnasti parallels) & Sit-up with medicine ball \\
Single-leg vertical jump & Theraband internal rotation (start & Med ball thow (sitt position) \\
& position). & \\
& Theraband internal rotation (finish & \\
position). & \\
& Theraband external rotation (finish & \\
\hline
\end{tabular}

Note: Depth jumps exercises were not applied between first to sixth week and in the last week.

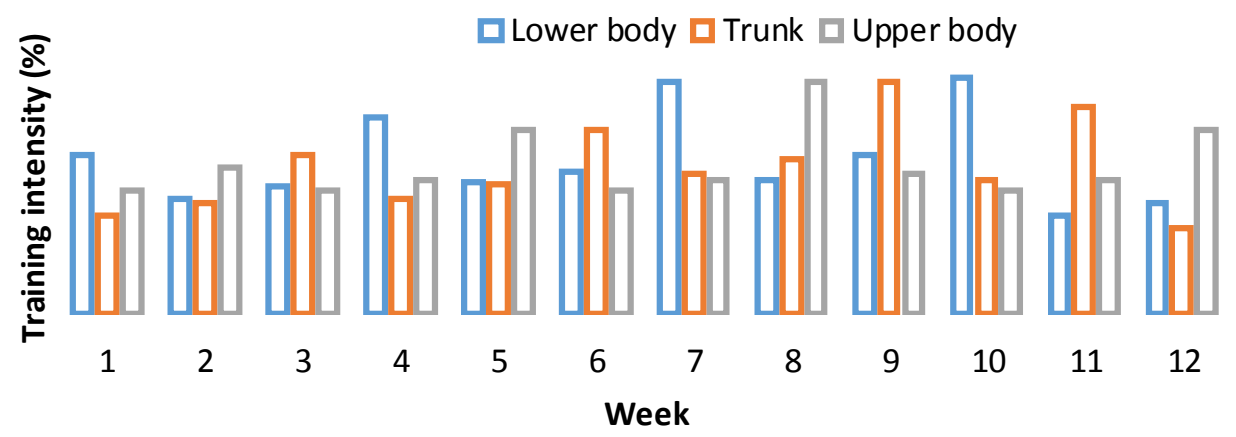

Figure 2. Weekly training intensity 
(interaction: CMJ, SBJ, TSJ, SMBTH; $p<0.05$ ). Similar results were observed in the tests between subjects (CMJ, SBJ, SMBTH; $p<0.05$, TSJ; $p>0.05)$. When analyzing the differences between the groups it was observed that the countermovement jump ( $\Delta \%: 28.90)$, standing broad jump ( $\Delta \%: 26.19)$, triple standing jump $(\Delta \%$ : 11.46) and standing medicine ball throw $(\Delta \%$ : 16.07) results of the experimental group (plyo-training) had higher development percentages compared to the countermovement jump ( $\% \Delta: 0.00)$, standing broad jump $(\% \Delta: 3.02)$, triple standing jump $(\% \Delta: 1.22)$ and standing medicine ball throw $(\% \Delta: 1.38)$ results of the control group (CMJ: $p=.00$, SBJ: $p=.00$, TSJ: $p=.06$, SMBTH: $\mathrm{p}=.00)$.

According to the results of Table 4, it was observed that pre- and post-test averages (tests within subjects) of the 10 meters run $(p<0.05)$ and 20 meters run $(p<0.05)$ values were statistically different according to measurement over time (interaction: $10 \mathrm{mRUN} ; \mathrm{p}<0.05,20 \mathrm{mRUN}$; $\mathrm{p}<0.05$ ). The results observed in the tests between subjects were not statistically different $(p>0.05)$. When analyzing the differences between the groups, it was observed that the 10 meters run test $(\Delta \%:-12.67)$ and 20 meters run test ( $\Delta \%$ : -10.90) of the experimental group (plyo-training) had higher development percentages compared to the 10 meters run $(\Delta \%:-3.05)$ and 20 meters run $(\Delta \%:-2.31)$ tests of the control group (10mRUN: $\mathrm{p}=.01,20 \mathrm{mRUN}$ : $\mathrm{p}=.14$ ).

According to the results of Table 5 it is seen that pre- and post-test averages (tests within subjects) of the

Table 2. Impact of plyometric training in the shot put technique performance level

\begin{tabular}{|c|c|c|c|c|c|c|c|c|c|}
\hline \multirow{2}{*}{ v } & \multirow{2}{*}{ Groups } & \multirow{2}{*}{ N } & Pre-test & Post-test & Total & \multicolumn{2}{|l|}{$"$} & \multirow{2}{*}{$\% \Delta$} & \multirow{2}{*}{$n 2$} \\
\hline & & & $\overline{\mathbf{X}} \pm \mathrm{SD}$ & $\overline{\mathbf{X}} \pm \mathrm{SD}$ & $\overline{\mathbf{X}} \pm \mathrm{SD}$ & $\mathbf{F}$ & $\mathbf{p}$ & & \\
\hline \multirow{4}{*}{ 吕 } & Plio-training & 110 & $5.7 \pm 1.14$ & $8.6 \pm 1.33$ & $7.2 \pm 1.5$ & \multirow{2}{*}{55.19} & \multirow{2}{*}{$.00 *$} & 50.88 & \\
\hline & Control Group & 110 & $5.9 \pm 1.26$ & $6.0 \pm 1.22$ & $5.95 \pm 0.05$ & & & 1.69 & \\
\hline & Total & 220 & $5.8 \pm 1.20$ & $7.3 \pm 1.81$ & $6.55 \pm 0.75$ & \multicolumn{4}{|c|}{$\checkmark F=1032.139 ; p=.00^{*}$} \\
\hline & & & & & < $F=844.2$ & $p=.00 *$ & & & \\
\hline
\end{tabular}

NOTE: $V$ - variable; *p<0.05. SHP: Shot put technique. $\bar{X} \pm S D$ : Mean and standard deviation. »: Tests of between-subjects' effects. ।: Testing effects within subjects (Greenhouse-Geisser). «: Interaction (Time*Groups). $\Delta \%$ : development \%. $\eta 2$ : partial eta squared, V: Variables

Table 3. Impact of plyometric training with respect to power ability (explosive force) factors

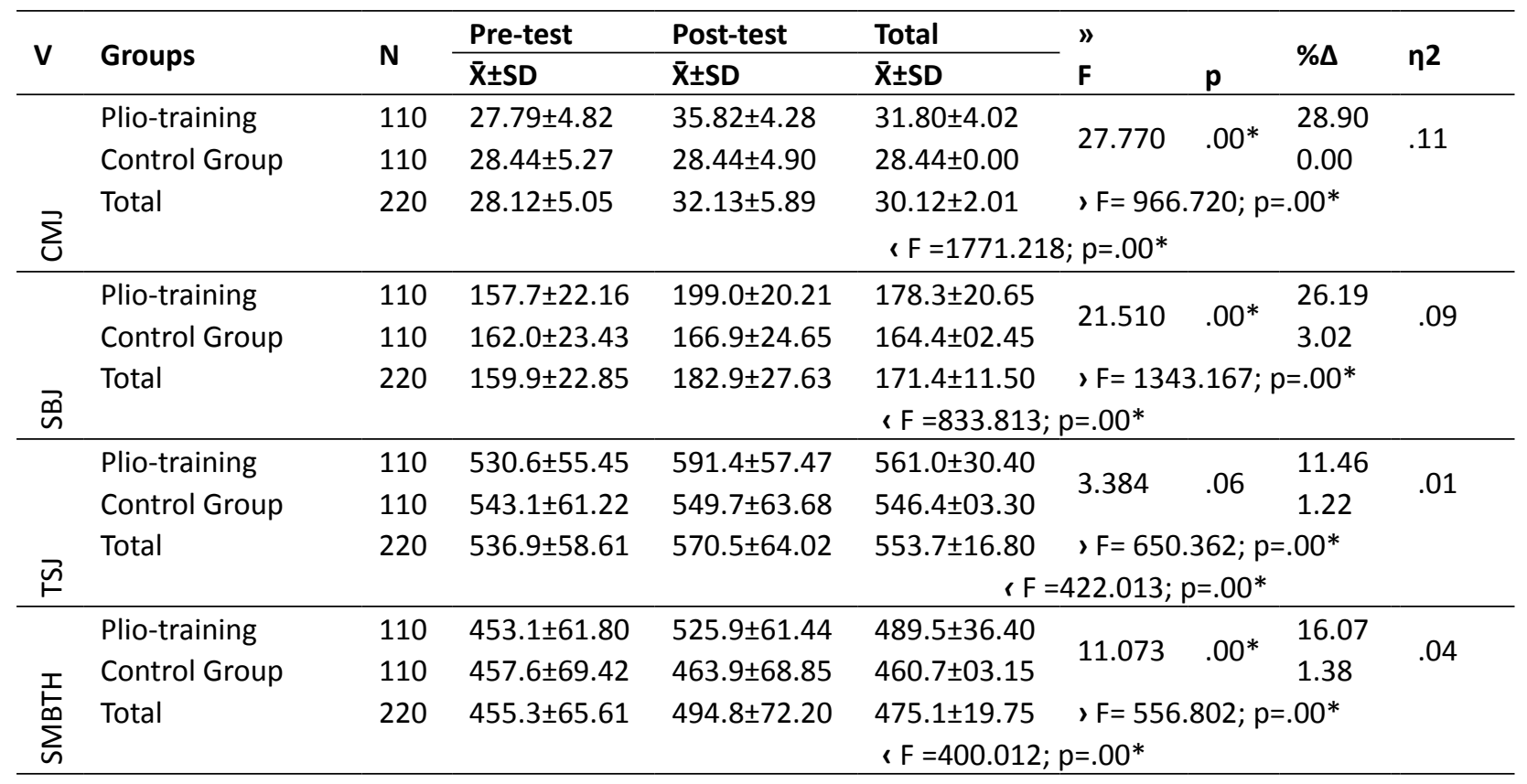

NOTE: $V$ - variable; ${ }^{*} p<0.05$. CMJ: Countermovement jump, SBJ: Standing broad jump, TSJ: Tipple standing jump, SMBTH: Standing medicine ball throw. $\bar{X} \pm S D$ : Mean and standard deviation. ": Tests of between-subjects' effects. ı: Tests of within subjects' effects (Greenhouse-Geisser). «: Interaction (Time*Groups). $\Delta \%$ : development \%. $\eta 2$ : partial eta squared. 
plate tapping $(\mathrm{p}<0.05)$, foot-tapping against the wall $(\mathrm{p}<0.05)$, sit ups in $30 \mathrm{sec}(\mathrm{p}<0.05)$ and push-ups in $30 \mathrm{sec}(\mathrm{p}<0.05)$ test values were statistically different according to measurement over time (interaction: PLT, FTAW, SUP30s, SMBTH; $\mathrm{p}<0.05)$. Similar results were observed in the SUP30s $(p<0.05)$ and PU30s $(p<0.05)$ between subjects. However, the results showed that in the PLT and FTAW results between subjects did not have any statistical difference $(\mathrm{p}>0.05)$. When analyzing the differences between the groups, it was observed that the plate tapping ( $\Delta \%$ : -12.43$)$, foot-tapping against the wall $(\Delta \%:-9.32)$, sit ups in $30 \mathrm{sec}(\Delta \%: 40.00)$ and push-ups in $30 \mathrm{sec}(\Delta \%: 45.83)$ test of the experimental group (plyotraining) had higher development percentages compared to the plate tapping ( $\Delta \%:-2.18)$, foot-tapping against the wall ( $\Delta \%:-2.25)$, sit ups in $30 \sec (\Delta \%: 2.01)$ and push- ups in $30 \mathrm{sec}(\Delta \%: 2.87)$ tests of the control group (PLT: $\mathrm{p}=.23$, FTAW: $\mathrm{p}=.45$, SUP30s: $\mathrm{p}=.00$, PU30s: $\mathrm{p}=.00$ ).

According to the results of Table 6, it was observed that pre- and post-test averages values (tests within subjects) of the dips $(\mathrm{p}<0.05)$ and flamingo balance $(\mathrm{p}<0.05)$ were statistically different according to measurement over time (interaction: $\mathrm{D}, \mathrm{FB}: \mathrm{p}=.00$ ). Similar results were observed in the $\mathrm{D}$ test between subjects $(\mathrm{p}<0.05)$. However, the results indicated that there was no statistical difference $(p>0.05)$ in the FB test between the subjects.

When analyzing the differences between the groups, it was observed that the dips $(\Delta \%: 70.51)$ and flamingo balance ( $\Delta \%:-50.00)$ test of the experimental group (plyotraining) had higher development percentages compared to the dips ( $\Delta \%$ : 5.95) and flamingo balance $(\Delta \%:-15.38)$ tests of the control group (D: $\mathrm{p}=.01, \mathrm{FB}: \mathrm{p}=.45$ ).

Table 4. Impact of plyometric training in acceleration ability factors

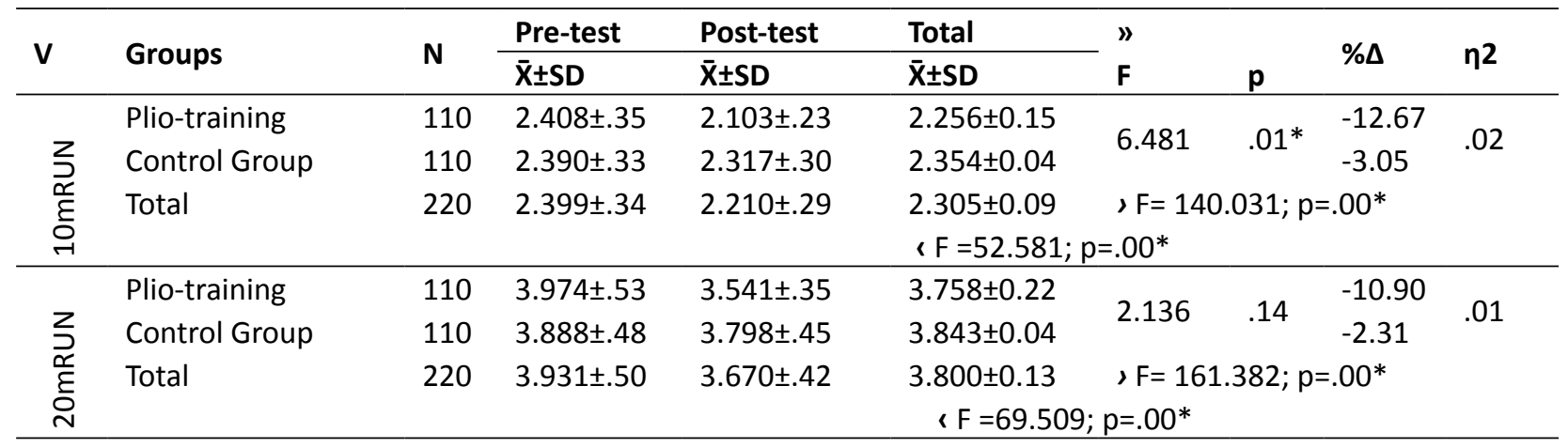

NOTE: $\vee$ - variable; ${ }^{*} p<0.05 .10 \mathrm{mRUN}$ : 10 Meters run, $20 \mathrm{mRUN}$ : 20 Meters run. $\overline{\mathrm{X}} \pm \mathrm{SD}$ : Mean and standard deviation. ": Tests of between-subjects' effects. ।: Tests of within subjects' effects (Greenhouse-Geisser). : Interaction (Time*Groups). $\Delta \%$ : development \%. $\eta 2$ : partial eta squared

Table 5. Impact of plyometric training in the speed of the upper and lower extremities and endurance in force factors

\begin{tabular}{|c|c|c|c|c|c|c|c|c|c|}
\hline \multirow{2}{*}{ v } & \multirow{2}{*}{ Groups } & \multirow{2}{*}{$\mathbf{N}$} & Pre-test & Post-test & Total & \multicolumn{2}{|l|}{$"$} & \multirow{2}{*}{$\% \Delta$} & \multirow{2}{*}{$\eta 2$} \\
\hline & & & $\overline{\mathbf{X}} \pm$ SD & $\overline{\mathrm{X}} \pm \mathrm{SD}$ & $\overline{\mathrm{X}} \pm \mathrm{SD}$ & $\mathbf{F}$ & $\mathbf{p}$ & & \\
\hline \multirow{4}{*}{$\bar{a}$} & Plio-training & 110 & $10.86 \pm 1.66$ & $09.51 \pm 1.32$ & $10.18 \pm 0.68$ & \multirow{2}{*}{1.404} & \multirow{2}{*}{.23} & -12.43 & \multirow{2}{*}{.00} \\
\hline & Control Group & 110 & $10.55 \pm 1.65$ & $10.32 \pm 1.63$ & $10.43 \pm 0.12$ & & & -2.18 & \\
\hline & Total & 220 & $10.71 \pm .166$ & $09.82 \pm 1.53$ & $10.31 \pm 0.45$ & $>F=25$ & $953 ; p$ & $.00^{*}$ & \\
\hline & & & \multicolumn{7}{|c|}{, $F=126.764 ; p=.00 *$} \\
\hline \multirow{4}{*}{ 主 } & Plio-training & 110 & $14.05 \pm 2.18$ & $12.74 \pm 2.11$ & $13.39 \pm 0.66$ & \multirow{2}{*}{.572} & \multirow{2}{*}{.45} & -9.32 & \multirow{2}{*}{.00} \\
\hline & Control Group & 110 & $13.77 \pm 2.31$ & $13.46 \pm 2.17$ & $13.61 \pm 0.15$ & & & -2.25 & \\
\hline & Total & 220 & $13.91 \pm 2.25$ & $13.10 \pm 2.16$ & $13.50 \pm 0.41$ & \multirow{2}{*}{\multicolumn{3}{|c|}{$\begin{array}{l}>F=110.088 ; p=.00 * \\
=41.907 ; p=.00 *\end{array}$}} & \\
\hline & & & & & & & & & \\
\hline \multirow{4}{*}{$\begin{array}{l}n \\
\text { ñ } \\
\\
\end{array}$} & Plio-training & 110 & $19.0 \pm 3.78$ & $26.6 \pm 3.85$ & $22.8 \pm 3.80$ & \multirow{2}{*}{26.932} & \multirow{2}{*}{$.00 *$} & 40.00 & \multirow{2}{*}{.11} \\
\hline & Control Group & 110 & $19.9 \pm 4.24$ & $20.3 \pm 4.17$ & $20.1 \pm 0.20$ & & & 2.01 & \\
\hline & Total & 220 & $19.5 \pm 4.03$ & $23.4 \pm 5.09$ & $21.4 \pm 1.95$ & \multicolumn{3}{|c|}{$\mathrm{F}=744.410 ; p=.00^{*}$} & \\
\hline & & & & & , $F=619.485$ & $=.00^{*}$ & & & \\
\hline \multirow{4}{*}{$\stackrel{\text { ֻ̆ }}{\stackrel{m}{D}}$} & Plio-training & 110 & $16.8 \pm 7.38$ & $24.5 \pm 7.36$ & $20.6 \pm 3.85$ & \multirow{2}{*}{8.783} & \multirow{2}{*}{$.00^{*}$} & 45.83 & \multirow{2}{*}{.03} \\
\hline & Control Group & 110 & $17.4 \pm 7.97$ & $17.9 \pm 8.02$ & $17.6 \pm 0.25$ & & & 2.87 & \\
\hline & Total & 220 & $17.1 \pm 7.67$ & $21.3 \pm 8.36$ & $19.1 \pm 2.10$ & \multirow{2}{*}{\multicolumn{3}{|c|}{, $F=510.631 ; p=.00 *$}} & \\
\hline & & & & & $<F=387.22$ & & & & \\
\hline
\end{tabular}

NOTE: $V$ - variable; ${ }^{*} p<0.05$. PLT: Plate tapping, (FTAW): Foot-tapping against the wall, SUP30s: Sit-ups in 30 secs, PU30s: Push-ups in $30 \mathrm{sec} . \bar{X} \pm S D$ : Mean and standard deviation. ": Tests of between-subjects' effects. ı: Tests of within subjects' effects (Greenhouse-Geisser). «: Interaction (Time*Groups). $\Delta \%$ : development \%. $\eta 2$ : partial eta squared. 
Table 6. Impact of plyometric training of the speed of the upper and lower extremities and endurance in force factors

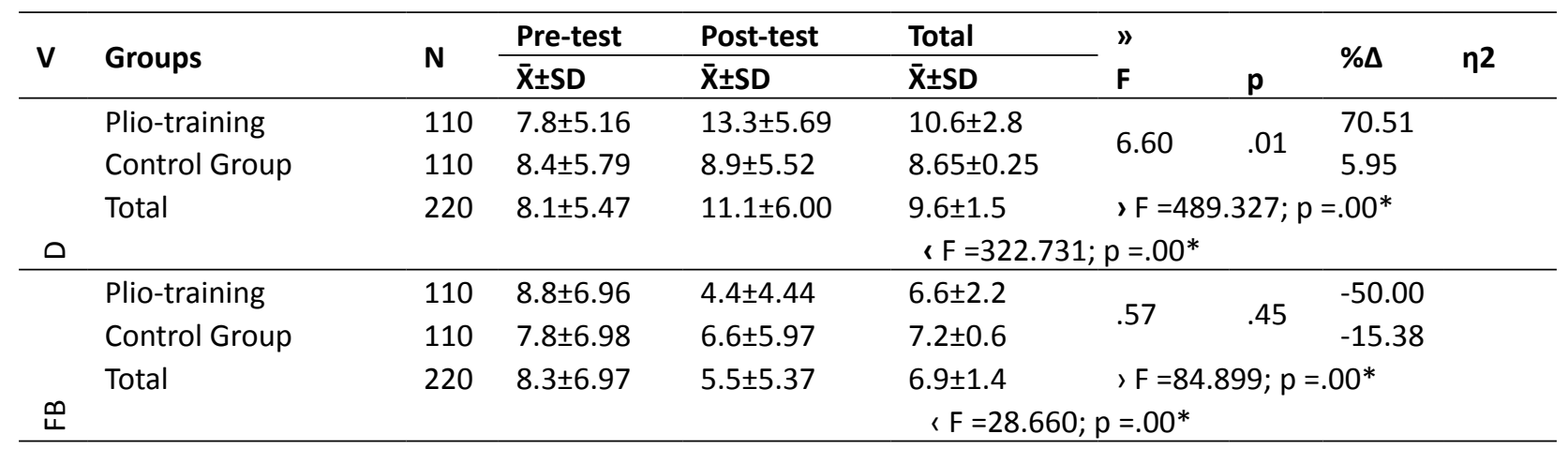

NOTE: $V$ - variable; ${ }^{*} p<0.05$. PLT: D: Dips, FB: Flamingo balance test. $\bar{X} \pm S D:$ Mean and standard deviation. »: Tests of between-subjects' effects. ı: Tests of within subjects' effects (Greenhouse-Geisser). «: Interaction (Time*Groups). $\Delta \%$ : development \%. $\eta 2$ : partial eta squared.

\section{Discussion}

In the study it was observed that pre- and post-test averages (within and between subjects) of the shot put technique $(\mathrm{p}<0.05)$ were statistically different according to measurement over time (interaction; $\mathrm{p}<0.05$ ). When analyzing the development percentage, it was observed that the performance of shot put technique $(\Delta \%: 50.8)$ of the experimental group compared to the shot put technique $(\Delta \%: 1.6)$ results of the control group had developed by $49.2 \%$.

If we refer to the research of Mustapha et al. [17], they also found significant statistical differences in the pre-test and post-test in the experimental sample for muscular strength and digital achievement in the shot put technique. According to the researchers, this result was due to the proposed training program based on scientific foundations of the application of physical exercises of quality that are related to the game, especially the use of the plyometric exercises ( 08 weeks \& 02 times in one week). Furthermore, T-test values for the experimental sample was also (2.57 and 3.04) larger than the tabulated T-test, which means there was also the existence of a significant difference between the pre-test and post-test calculated average in favor of the post-test group [17].

Similar results in the shot put technique were also observed in analyzing the impact of the plyometric training program in the motor abilities related to the shot put technique. Applied plyometric training program benefits were not just in the shot put technique, but also improved all motor abilities related to the technique such a power, strength endurance, speed, and acceleration. Thus, the development of the shot put technique occurred by the increase in motor abilities related to the shot put technique as a result of the plyometric training program.

Referring to the literature, ten weeks of strength and power training induced significant increases in the shot put throw, standing long jump work production, and sprinting performance. These changes were accompanied by adaptations in muscle thickness and fascicle length. The current data suggest that examination of muscle thickness and performance in explosive field tests may partly predict the training-induced increase in actual track and field throwing performance [18]

When the same analyses were applied in the explosive force factors, it was observed that the differences within subjects and between subjects of the countermovement jump $(\mathrm{p}<0.05)$, standing broad jump $(\mathrm{p}<0.05)$, triple standing jump $(\mathrm{p}<0.05)$ and standing medicine ball throw $(p<0.05)$ test values were statistically different $(p<0.05)$. When analyzing the development percentage, it was observed that the countermovement jump ( $\Delta \%: 28.9)$, standing broad jump $(\Delta \%: 26.1)$, triple standing jump $(\Delta \%: 11.4)$ and standing medicine ball throw $(\Delta \%: 16.0)$ test results of the experimental group (plyo-training); compared to the countermovement jump ( $\Delta \%$ : 0.00$)$, standing broad jump ( $\Delta \%: 3.0)$, triple standing jump ( $\Delta \%$ : $1.2)$ and standing medicine ball throw $(\Delta \%: 1.3)$, have shown higher development percentages (CMJ: 28.9\%, SBJ: $23.1 \%$, TSJ: 10.2\%, SMBTH: 14.7\%).

Based on the literature, we can see that there were statistically significant differences in post-test between the control and experimental sample in favor of the experimental group. This indicates that plyometric exercises were more effective in improving performance in the shot put through the use of medicine balls and iron balls with different weights. This actually confirms the effectiveness of using plyometric exercises leads to an improvement in physical abilities and performance in sports activities $[19,20]$. If we see the literature, we can verify that a combined plyometric and squat training program significantly increased vertical jump results compared to training with squats or plyometric alone [21].

With regards to acceleration abilities, it was observed that within subjects the 10 meters run $(p<0.05)$ and 20 meters run $(p<0.05)$ test values were statistically different according to measurement over time. The results observed in the tests between subjects were not statistically different $(\mathrm{p}>0.05)$.

When analyzing the development percentage, it was observed that the 10 meters run test $(\Delta \%:-12.6)$ and 20 meters run $(\Delta \%:-10.9)$ test of the experimental group (plyo-training) have shown higher development percentages compared to the 10 meters run $(\Delta \%:-3.0)$ and 20 meters run $(\Delta \%:-2.3)$ tests of the control group $(10 \mathrm{~m}$ 
run: $9 \%, 20 \mathrm{~m}$ run: $8.6 \%$ ).

The literature showed that after a plyometric training program of 10 weeks duration found that the jump program increased the velocity for running distances of $0-30,10-20$, and 20-30 [22]. Results of several investigations involving adults suggest that combining plyometric training with other training programs may be useful for enhancing muscular performance and running velocity $[21,23,24]$.

Analysis of speed, strength endurance and balance, showed that within subjects and between subjects of the plate tapping $(\mathrm{p}<0.05)$, foot-tapping against the wall $(p<0.05)$, sit ups in $30 \mathrm{sec}(\mathrm{p}<0.05)$ and push-ups in 30 $\sec (\mathrm{p}<0.05)$ tests, were impacted by plyometric training applied on the study sample $(\mathrm{p}<0.05)$.

When analyzing the development percentages, it was observed that plate tapping $(\Delta \%:-12.4)$, foottapping against the wall $(\Delta \%:-9.3)$, sit ups in $30 \mathrm{sec}$ $(\Delta \%: 40.0)$ and push-ups in $30 \mathrm{sec}(\Delta \%: 45.8)$ tests of the experimental group (plyo-training) showed higher development percentages compared to the plate tapping $(\Delta \%$ : -2.1$)$, foot-tapping against the wall $(\Delta \%:-2.2)$, sit ups in $30 \operatorname{secs}(\Delta \%: 2.0)$ and push-ups in $30 \sec (\Delta \%: 2.8)$ tests of the control group (PLT: $10.3 \%$, FTAW: $7.1 \%$, SUP30s: $38.0 \%$, PU30s: $43.0 \%$ ).

Kontou et al. (2018) in their study confirms that after isometric push-ups, participants have a higher percentage increase in shot-put performance [25]. Moreover, within subjects and between subjects regarding the dips and flamingo balance tests, values were statistically different $(p<0.05)$. When analyzing the development percentage, it was observed that the dips $(\Delta \%: 70.5)$ and flamingo balance $(\Delta \%:-50.0)$ test of the experimental group (plyotraining) had higher development percentages compared to the dips $(\Delta \%: 5.9)$ and flamingo balance $(\Delta \%:-15.3)$ tests of the control group (D: $64.6 \%$, FB: $34.7 \%$ ).

The research showed that when the effects of psychomotor training on balance was taken into consideration, a statistically significant difference was found between pre-test $(\overline{\mathrm{x}} 4.59)$ and post-test $(\overline{\mathrm{x}} 1.98)$ in the training group (experimental group) $(\mathrm{p}<0.01)$. No statistically significant difference was found between the balance pre-test ( $\overline{\mathrm{x}} 4.54)$ and post-test $(\overline{\mathrm{x}} 3.69)$ in the nontraining group (control group) $(\mathrm{p}<0.05)$ [26]

\section{Conclusion}

In conclusion, the impact of the plyometric training program on motor abilities related to the shot put technique also observed similar results as the training program's impact on the shot put technique. The applied plyometric training program benefits were not just in the shot put technique but also improved all motor abilities related to the shot put technique such as power, strength endurance, speed and acceleration. Therefore, the development of the shot put technique occurred by an increase in motor abilities related to the shot put technique as a result of the plyometric training program.

\section{Conflict of interests}

No potential conflict of interest was reported by the authors.

\section{References}

1. Halliwell B, Gutteridge JMC. Free Radicals in Biology and Medicine, Oxford University Press; 1999.

2. Driss T, Vandewalle H, Monod H. Maximal power and forcevelocity relationship during cycling and cranking exercises in volleyball players. $J$ Sports Med Phys Fitness, 1998; (38): 286-293.

3. Durand S, Beaune B, Gagé G, Ripamonti M, Rahmani A. Puissance anaérobie des membres inférieurs chez des joueurs de tennis de deuxième et troisième série [Anaerobic Lower Limb Potency in Second and Third Round Tennis Players]. Sci Sports, 2009; (24):320-322. (In French). https://doi.org/10.1016/j.scispo.2008.12.002

4. Judge LW. The Complete Track and Field Coaches' Guide to Conditioning for the Throwing Events. Monterey, CA: Coaches Choice Publishing; 2008.

5. Judge LW, Burke JM, Moreau C. Neural adaptations with sports specific resistance with highly skilled athletes. J Sport Sci, 2003; (21): 419-427. https://doi.org/10.1080/0264041031000071173

6. Young M. Preparing for the specific neuromuscular and biomechanical demands of the javelin throw. National Throws Coaches Association; 2007.

7. Stone MH, Sanborn K, O'Bryant HS, Hartman M, Stone ME, Proulx $\mathrm{C}$, et al. Maximum strengthpower performance relationships in collegiate throwers. J Strength Cond Res, 2003; (17): 739-745. https://doi.org/10.1519/00124278-200311000-00019

8. Terzis G, Georgiadis G, Vassiliadou E, Manta P. Relationship between shot put performance and triceps brachii fiber type composition and power production. Eur $J$ Appl Physiol, 2003;90:10-5. https://doi.org/10.1007/s00421-003-0847-x

9. Chaouachi A, Brughelli M, Levin G, Boudhina NB, Cronin J, Chamari K. Anthropometric physiological and performance characteristics of elite teamhandball players. $J$ Sports Sci, 2009;(15):151-7. https://doi.org/10.1080/02640410802448731

10.Nešić G, Ilić D, Majstorovic N, Grbic V, Osmankac N. Effects of training on basic and specific motor abilities of volleyball players aged 13-14 years. SportLogia, 2013; 9(2): 119-27. https://doi.org/10.5550/sgia.130902.en.007N

11.Bjelica D, Fratrić F. Sport training - theory, metodics and diagnostics. Faculty of sport and physical education; 2011.

12.Badrić M. The correlation between kinesiological activities in free time and motor skills of high school students. 2011. (In Croatian).

13.Günay M, Tamer K, Cicioğlu İ, Şıktar E. Spor Fiziyolojisi ve Performans Ölçüm Testleri [Sports Physiology and Performance Measurement Tests]. Ankara: Gazi Kitabevi Tic. Ltd. Şti; 2017. (In Turkish).

14.Baumgartner TA, Oh S, Chung H, Hales D. Objectivity, Reliability, and Validity for a Revised Push-Up Test Protocol. Measurement in Physical Education and Exercise Science, 2002; 6(4): 225-42. https://doi.org/10.1207/S15327841MPEE0604_2

15.Hashim A. Objectivity, Reliability and Validity of the $90^{\circ}$ Push-Ups Test Protocol Among Male and Female Students of Sports Science Program. Journal of Physical Education and Sport, 2012; 12(1): 103-6. 
16.Coyne J. Influence of anthropometric and upper body strength qualities on surfboard paddling kinematics. [Thesis]. Edith Cowan University; 2015.

17.Mustapha B, Houcine B, Touati A, Djamel M. Effectiveness of plyometric exercises to improve muscular strength and digital achievement for students in shot put. International Journal of Physical Education, Fitness and Sports, 2019; (2): 36-41. https://doi.org/10.26524/ijpefs 1925

18.Zaras N, Stasinaki A, Methenitis S, Terzis G. Track and field throwing performance prediction: Training intervention, muscle architecture adaptations and field tests explosiveness ability. Journal of Physical Education and Sport, 2019; (2): $436-443$.

19.Mehdi Kadhim Ali. Effect of the plyometric training and weight training to develop the explosive strength and rapid force to improve the performance in shot put, Journal of Physical Education and Sports Science, 2002; (2): 7-22.

20.Bensikaddour H, Benzidane H, Touati AB, Mokrani D. The effect of using plyometric exercises to improve some physical abilities and performance in the triple jump (hop, step, jump). The Swedish Journal of Scientific Research, 2015; (2): 53-61.

21.Adams K, O'Shea P, O'Shea KL, Climstein M. The effect of six weeks of squat, plyometric andsquatplyometric training on power production. Journal of Applied Sport Science Research, 1992; 6(1): 36-41. https://doi.org/10.1519/00124278-199202000-00006
22.Kotzamanidis C. Effect of plyometric training on running performance and vertical jumping in prepubertal boys. J Strength Cond Res, 2006; (2): 441-445. https://doi.org/10.1519/00124278-200605000-00034

23.Fatouros I, Jamurtas Z, Leontsini D, Taxildaris K,Aggelousis $\mathrm{N}$, Kostopoulos N, et al. Evaluation of plyometric exercises training, weight training and their combination on vertical jump performance and leg strength. The Journal of Strength and Conditioning Research, 2000; (14): 470-476. https://doi.org/10.1519/00124278-200011000-00016

24.Miller GM, Herniman JJ, Ricard DM, Cheatham CC, Michael JT. The effects of a 6 -week plyometric training program on agility. Journal of Sports Science and Medicine, 2006; (5): 459-465.

25.Kontou EI, Berberidou FT, Pilianidis TC, Mantzouranis NI, Methenitis SK. Acute Effect of Upper and Lower Body Postactivation Exercises on Shot Put Performance. Journal of Strength and Conditioning Research, 2018; (4): 970-982. https://doi.org/10.1519/JSC.0000000000001982

26. Yazar Soyadı YA, Yaman N, Berisha $M$, Hergüner G, Yaman Ç, Önal A. Examining the effect of psychomotor training on the coordination, agility and balance in 10-11 year-old girls. International Refereed Academic Journal of Sports, 2016:137-137. https://doi.org/10.17363/SSTB.20162124346

\section{Information about the authors:}

Agron Thaqi; Doctoral student; https://orcid.org/0000-0001-7306-0088; athaqi@hotmail.com; Kinesiology Department, Physical Education and Sport Faculty, Tetovo State University, North Macedonia.

Milaim Berisha; (Corresponding Author); https://orcid.org/0000-0002-0353-7247; milaimberisha3@gmail.com; Coaching Department, School of Physical Education and Sport, Istanbul Gelisim University, Istanbul, Turkey.

Isa Asllani; https://orcid.org/0000-0003-3584-6906; isa.asllani@unite.edu.mk; Kinesiology Department, Physical Education and Sport Faculty, Tetovo State University, North Macedonia.

Cite this article as:

Thaqi A, Berisha M, Asllani I. The effect of plyometric training on performance levels of the shot put technique and its related motor abilities. Pedagogy of Physical Culture and Sports, 2021;25(3):144-151.

https://doi.org/10.15561/26649837.2021.0301

This is an Open Access article distributed under the terms of the Creative Commons Attribution License, which permits unrestricted use, distribution, and reproduction in any medium, provided the original work is properly cited (http://creativecommons.org/licenses/by/4.0/deed.en).

Received: 20.09.2020

Accepted: 04.11.2020; Published: 30.06.2021 